\title{
Effects of Insulin on Ovine Fetal Leucine Kinetics and Protein Metabolism
}

\author{
J. Ross Milley \\ Division of Neonatology, Department of Pediatrics, University of Utah School of Medicine, Salt Lake City, Utah 84132
}

\begin{abstract}
Fetuses of eight pregnant ewes (114-117 d of gestation) were used to study whether fetal insulin concentration affects fetal protein accretion and, if so, whether such changes are caused by effects on protein synthesis or protein breakdown. Fetal leucine kinetics were measured by infusion of $\left[1-{ }^{14} \mathrm{C}\right]$ leucine during each of three protocols: (I) low vs. normal insulin concentration; (II) low vs. high insulin concentration; and (III) low vs. high insulin concentration during amino acid infusion to keep leucine concentration constant. Fetal leucine concentration $(233 \pm 20$ vs. $195 \pm 18 \mu \mathrm{M})$ and clearance $(48.3 \pm 4.4$ vs. $54.2 \pm 5.5 \mathrm{ml} / \mathrm{kg}$ per $\mathrm{min}$ ) were the only aspects of fetal leucine kinetics that changed during protocol I. During protocol II, insulin infusion decreased fetal leucine concentration $(222 \pm 22$ vs. 175 \pm 22 ), decreased fetal leucine disposal (11.63 \pm 0.89 vs. $12.55 \pm 0.89 \mu \mathrm{mol} / \mathrm{kg}$ per min), increased leucine clearance (48.0 \pm 4.2 vs. $57.6 \pm 6.5 \mathrm{ml} / \mathrm{kg}$ per $\mathrm{min}$ ), decreased leucine decarboxylation (1.77 \pm 0.17 vs. $2.04 \pm 0.21 \mu \mathrm{mol} / \mathrm{kg}$ per $\mathrm{min})$, decreased nonoxidative leucine disposal $(9.81 \pm 0.78$ vs. $10.51 \pm 0.74 \mu \mathrm{mol} / \mathrm{kg}$ per $\mathrm{min}$ ), decreased release of leucine from fetal protein $(7.43 \pm 1.08$ vs. $8.38 \pm 0.84 \mu \mathrm{mol} / \mathrm{kg}$ per $\mathrm{min}$ ), but did not change the accretion of leucine into protein. In contrast, when leucine concentrations $(205 \pm 25$ vs. 189 \pm 23$)$ were maintained (protocol III), insulin infusion did not change fetal leucine disposal, decarboxylation, or nonoxidative disposal although leucine clearance still rose $(55.4 \pm 5.0$ vs. $64.4 \pm 5.9 \mathrm{ml} / \mathrm{kg} / \mathrm{min}$ ). Fetal release of leucine from protein, however, decreased $(7.46 \pm 0.83$ vs. $8.57 \pm 0.71 \mu \mathrm{mol} / \mathrm{kg}$ per $\mathrm{min})$ and the accretion of leucine into protein increased (3.27 \pm 0.30 vs. $1.80 \pm 0.32 \mu \mathrm{mol} / \mathrm{kg} / \mathrm{min})$. These findings show that insulin decreases fetal protein breakdown. If insulininduced hypoaminoacidemia occurs, protein synthesis decreases so that no net accretion of protein occurs. If fetal amino acid concentrations are maintained, however, insulin itself does not affect protein synthesis, and fetal protein accretion increases. (J. Clin. Invest. 1994. 93:1616-1624.) Key words: fetus • fetal growth • protein breakdown - protein synthesis • insulin
\end{abstract}

\section{Introduction}

In adults, insulin plays an important anabolic role in the regulation of protein and amino acid metabolism. In vitro studies

Address correspondence to Dr. J. Ross Milley, Division of Neonatology, Department of Pediatrics, University of Utah School of Medicine, 50 N. Medical Drive, Salt Lake City, UT 84132.

Received for publication 14 May 1993 and in revised form $22 \mathrm{De}$ cember 1993.

J. Clin. Invest.

(c) The American Society for Clinical Investigation, Inc.

0021-9738/94/04/1616/09 \$2.00

Volume 93, April 1994, 1616-1624 have shown that insulin promotes both amino acid uptake (1) and protein breakdown in rat muscle (2). In vivo, however, insulin's effects are somewhat different. Insulin infusion into adult dogs (3) or adult human volunteers (4-7) decreases leucine turnover and oxidation, and depresses protein synthesis and degradation. Protein balance (synthesis minus breakdown) was minimally affected by hyperinsulinemia in these experiments (7), an effect seemingly at variance with insulin's role as an anabolic hormone. However, these studies have consistently also shown that insulin infusion not only increases insulin concentration but markedly decreases leucine concentration (3-7). When, concomitant with insulin infusion, amino acids are infused to keep leucine concentration constant, neither protein synthesis nor leucine oxidation decline $(4,6)$. In contrast, protein degradation decreases even more when leucine concentration is maintained than when insulin alone is infused. Because protein degradation decreases while synthesis remains constant, protein balance, i.e., the accretion of leucine into proteins, increases during hyperinsulinemia at constant leucine concentration (4), an effect contrasting to that of insulin infusion alone.

Insulin has long been felt to be an important promoter of fetal growth, a conviction fostered by the associations of fetal growth retardation with fetal insulin deficiency (8) and of fetal overgrowth with fetal hyperinsulinism (9). If the manner of insulin action in fetal life were analogous to that in adults, insulin should augment protein balance primarily by decreasing fetal protein degradation. However, the few studies of the effect of insulin on fetal protein metabolism in vivo provide results that contradict this supposition. Young and her colleagues ( 10 ) showed that fetal lamb amino acid concentrations decreased and cardiac muscle protein synthetic rates increased in response to insulin infusion. Johnson et al. (11) measured protein turnover in fetal rat tissues and concluded that the major effect of fetal hyperinsulinemia was to increase protein synthesis in certain tissues without affecting protein breakdown. Most recently, Liechty et al. (12) found that, in their fed ewes, fetal hyperinsulinemia had no effects on fetal protein synthesis, breakdown, or accretion. They concluded from their experiments that the mode of action of insulin in fetuses is different from that in adults. However, in these experiments, fetal leucine concentrations fell by $19 \%$ in association with fetal insulin infusion. They did not account for the concomitant effect that this hypoaminoacidemia might have had on fetal protein metabolism.

Therefore, before the response of fetal protein metabolism to hyperinsulinemia is deemed unique, the effect of hypoaminoacidemia on the response of fetal protein metabolism to insulin must be investigated. This study was undertaken to discover if fetal protein accretion is indeed affected by fetal insulin concentration alone in non-fasted ewes and, if so, whether such changes are the result of changes in protein breakdown, as in adults, or changes in protein synthesis, a mode of action that would be uniquely fetal. 


\section{Methods}

Animals. The eight pregnant ewes ( six singleton pregnancies, two twin pregnancies) used for this study weighed $62.6 \pm 3.5 \mathrm{~kg}$ and had gestational ages between 114 and $117 \mathrm{~d}$ (Torell Ranch, Ukiah, CA). They were premedicated with intravenous ketamine $(10 \mathrm{mg} / \mathrm{kg})$, intubated, and placed under general anesthesia (about $2 \%$ isofluorane). The maternal abdomen was incised in the midline and a hysterotomy was performed over the neck of the fetus, the fetal skin was incised and two catheters were placed in one jugular vein. The fetal and uterine incisions were closed and a second incision was made over the region of the fetal abdomen. The fetal skin was incised 2-3 mm from the umbilical ring and a catheter was placed in the umbilical vein. The fetal and uterine incisions were again closed and the uterus reopened over the fetal hindlimbs. Each fetal hindlimb was withdrawn and catheters were placed via a hindlimb artery and two hindlimb veins to the abdominal aorta and inferior vena cava, respectively. The hysterotomy and maternal abdominal incisions were closed, and the catheters tunneled to the maternal flank where they were stored in a pouch until needed.

Before operation and for $3 \mathrm{~d}$ postoperatively, each animal received intramuscular antibiotics ( $2.5 \mathrm{ml}$ of Di-Trim, $48 \%$ injection, containing $80 \mathrm{mg} / \mathrm{ml}$ trimethoprim and $400 \mathrm{mg} / \mathrm{ml}$ sulfadiazine, Syntex Animal Health, Inc., West Des Moines, IA). The animals were allowed to recover for $6 \mathrm{~d}$ before experiments were started. Catheter patency was ensured by filling the catheters with saline $(0.9 \%)$ containing heparin $(100 \mathrm{U} / \mathrm{ml})$ every other day. Animals had free access to food and water during recovery and throughout all experiments. On completion of study protocols, the ewe and fetus were killed by barbiturate overdose (Beuthanasia-D Special, Schering, Kenilworth, NJ). The fetus was then weighed and all catheter positions confirmed at autopsy. Fetal weights were $2.95 \pm 0.14 \mathrm{~kg}$ at autopsy. To allow comparison of the data from this report to other published data, variables are normalized to the weight of the fetus at autopsy. We did not correct for growth over the $4 \frac{1}{3} \mathrm{~d}$ of study ( $\sim 380 \mathrm{~g}$, or $18 \%$ of original fetal body weight) as the amount of growth for a specific fetus on any given day could not be known. However, this lack of correction for fetal growth could not have influenced the conclusions of this study because we made no comparisons between days.

Experimental design. Three experimental protocols detailed below (Fig. 1) were performed in each of the eight animals. Each protocol was separated from the next by at least $36 \mathrm{~h}$ of recovery. Each animal was

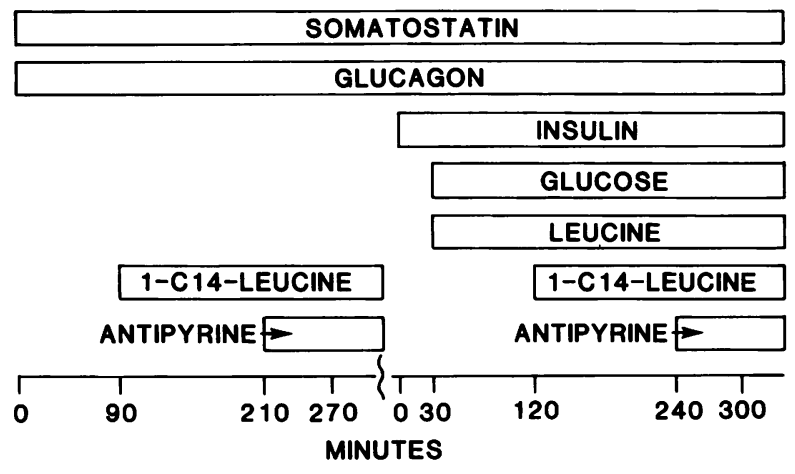

Figure 1. Outline of experimental design. Each protocol consisted of somatostatin and glucagon infusions throughout the entire experiment. The control measurements for all three protocols were made after $3 \mathrm{~h}$ of radioactive leucine infusion and $1 \mathrm{~h}$ of antipyrine infusion. To make measurements during hyperinsulinemia, insulin infusion was begun, followed by a variable glucose infusion to maintain euglycemia. Insulin was infused during protocol I to return fetal plasma insulin concentration to normal (i.e., not infused with somatostatin and glucagon) values. During protocols II and III, insulin was infused at a rate causing hyperinsulinemia. During protocol III, Trophamine, a commercial amino acid mixture, was infused to maintain constant leucine concentration. represented by each of the desired comparisons: protocol I, low vs. normal insulin concentration; protocol II, low vs. high insulin concentration; and protocol III, low vs. high insulin concentration during amino acid infusion to keep leucine concentration constant. To reduce variation of endogenous pancreatic hormone secretion, experiments were initiated by beginning venous infusions of somatostatin (Sigma Chemical Co., St. Louis, MO) at $1.5 \mu \mathrm{g} / \mathrm{kg}$ per min after a loading bolus of $15 \mu \mathrm{g} / \mathrm{kg}$ and glucagon (Eli Lilly \& Co., Indianapolis, IN) at $10 \mathrm{ng} / \mathrm{kg}$ per min after a loading bolus of infusion of $10 \mathrm{ng} / \mathrm{kg}$ into the fetus. Weight was estimated based on intrauterine growth curves for the sheep fetus (13). Preliminary experiments showed that by $90 \mathrm{~min}$ of such infusion, fetal plasma insulin and glucagon concentrations were constant. Consequently, after $90 \mathrm{~min}$ of somatostatin and glucagon infusion, we began infusion of $\left[1-{ }^{14} \mathrm{C}\right]$ leucine in sterile saline into the fetal inferior vena cava catheter at $5.5 \times 10^{6} \mathrm{dpm} / \mathrm{min}$. This infusion was continued for $180 \mathrm{~min}$, sufficient time for leucine specific activity to become constant $(14) .2 \mathrm{~h}$ after starting the $\left[1-{ }^{14} \mathrm{C}\right]$ leucine infusion, an infusion of antipyrine ( $24 \mathrm{mg} / \mathrm{kg}$ in sterile $0.9 \%$ saline ) at $0.2 \mathrm{ml} /$ min was started into the fetal inferior vena cava catheter. $1 \mathrm{~h}$ later, blood was drawn simultaneously from the fetal umbilical vein and aorta for analysis of whole blood contents of glucose, antipyrine, leucine, and $\alpha$-ketoisocaproate, and also for radioactivity as ${ }^{14} \mathrm{CO}_{2},\left[{ }^{14} \mathrm{C}\right]$ leucine, and $\left[{ }^{14} \mathrm{C}\right] \alpha$-ketoisocaproate. In addition, arterial plasma was analyzed for $\alpha$-ketoisocaproate specific activity. Two additional similar sets of blood samples were drawn at $\sim 15$-min intervals. Values from these three samples were averaged before calculations. Arterial blood was taken for analysis of hematocrit, $\mathrm{pH}, \mathrm{PCO}_{2}, \mathrm{PO}_{2}$, and plasma insulin and glucagon concentrations as the last set of samples was obtained. After the blood sampling procedure, the fetus was transfused with an amount of maternal blood equal to that removed.

To increase fetal insulin concentration, insulin (U100 Iletin, Eli Lilly \& Co. was infused $(10 \mathrm{mU} / \mathrm{ml}$, protocol I or $40 \mathrm{mU} / \mathrm{ml}$, protocols II and III in $90 \%$ sterile $0.9 \%$ saline: $10 \%$ maternal plasma) into a fetal vein at 0.25 (protocol I) or $1.25 \mathrm{mU} / \mathrm{kg}$ per $\mathrm{min}$ (protocols II and III) after a 10-min priming infusion (15). Samples of fetal serum were analyzed for glucose concentration at the beginning of the insulin infusion and every 15 min until the sampling process was again performed. Glucose (as 5\% dextrose, protocol I or 10\% dextrose, protocols II and III) was infused intravenously (15) as needed to maintain constant fetal glucose concentration (Fig. 2). When fetal glucose concentration was consistently within $0.012 \mathrm{mM}$ of its value before insulin infusion, the $\left[1-{ }^{14} \mathrm{C}\right]$ leucine infusion was restarted as described above followed 2 $\mathrm{h}$ later by the antipyrine infusion. After an additional hour, three sets of blood samples identical to those previously described were obtained. For protocol III, fetal serum leucine concentration was measured before beginning the insulin infusion and every $15 \mathrm{~min}$ after that until the end of the protocol. Once fetal glucose concentration had become stable during the insulin infusion, an intravenous infusion of $10 \%$ Trophamine (Kendall McGaw Laboratories, Irvine, CA; leucine concentration, $10.67 \mathrm{mM}$ ) was begun and adjusted to maintain constant fetal leucine concentration (Fig. 3). Fetal $\left[1-{ }^{14} \mathrm{C}\right]$ leucine infusion was started when fetal serum leucine concentration had stabilized during the Trophamine infusion. The remainder of the protocol was as described for protocol II.

Chemical analyses. Methods for measurement of fetal whole-blood concentrations of leucine and $\alpha$-ketoisocaproate, leucine and $\alpha$-ketoisocaproate whole-blood radioactivity, and fetal plasma specific activities of $\alpha$-ketoisocaproate have been described (14). Blood ${ }^{14} \mathrm{CO}_{2}$ was measured by a modification (14) of the method of Hinks et al. (16). Whole-blood antipyrine was measured by a previously described (14) modification of the HPLC method of Teunissen et al. (17). Wholeblood concentration of glucose was measured using previously described methods (18). Fetal serum glucose was analyzed with a glucose analyzer (glucose analyzer model 23A, Yellow Springs Instruments, Yellow Springs, $\mathrm{OH}$ ). Rapid measurements of fetal serum leucine were by the method of Brown et al. (19). Blood oxygen concentration was calculated from measurements of oxygen saturation and hemoglobin content (Hemoximeter OSM III, Radiometer, Copenhagen, DK). 


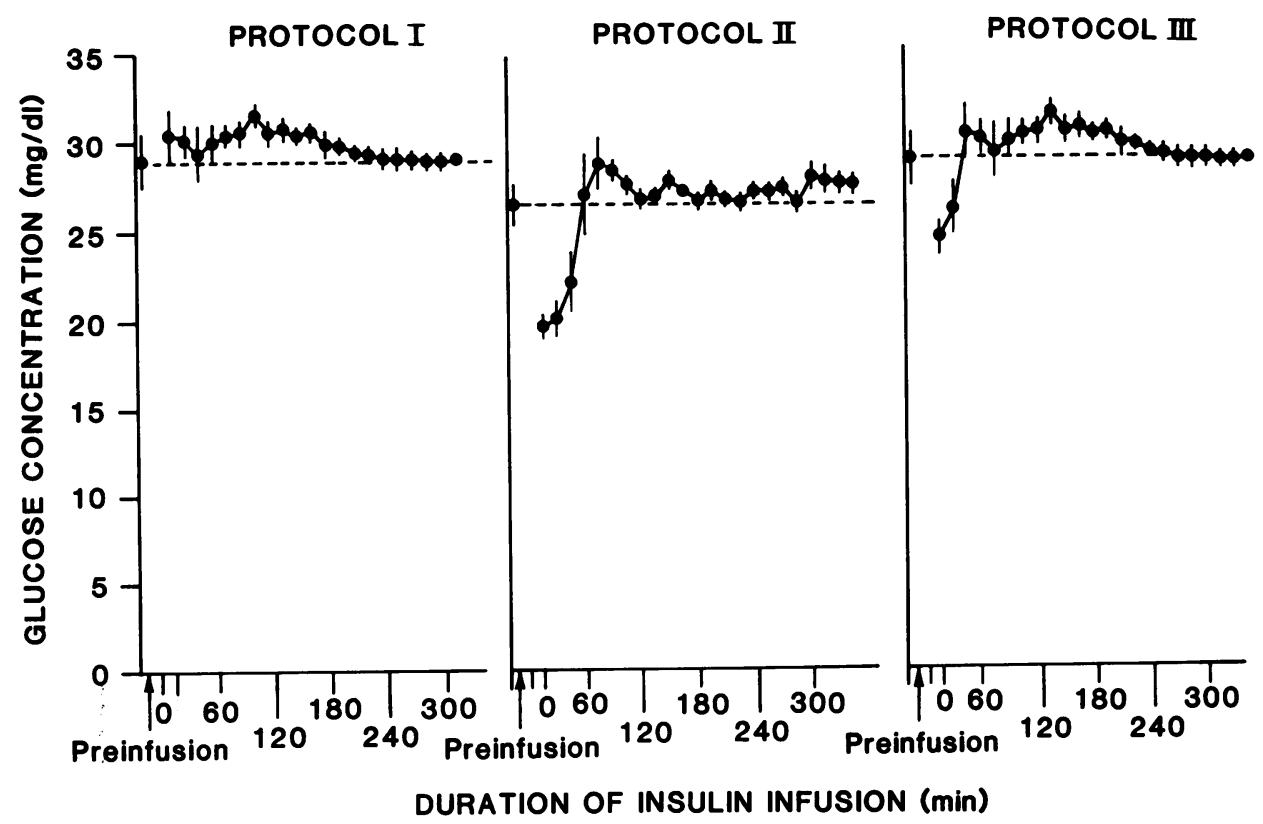

Figure 2. Fetal serum glucose concentrations for eight fetuses during the insulin infusion portion of each of the three experimental protocols. Samples (shown as the mean \pm SEM) were taken before insulin infusion began. The euglycemic clamp technique (see Methods) was designed to return the serum glucose concentration to this value (shown as a dashed line) during the insulin infusion. Serum glucose values were monitored every 15 min until the sampling procedure (see Methods) began.

Blood gases and $\mathrm{pH}$ were measured at $39^{\circ} \mathrm{C}$ with standard electrodes (ABL30 acid-base analyzer, Radiometer). Hematocrits were measured by the microhematocrit method. Insulin and glucagon were measured by radioimmunoassay (ICN Biomedicals Inc., Costa Mesa, CA ). Interassay and intrassay coefficients of variation were 15 and $5 \%$ respectively for insulin assays, and 10 and $3 \%$, respectively, for glucagon assays. To reduce the effect of interassay variability on the results of this experiment, all samples from each experiment were analyzed together.

Calculations. Umbilical blood flow was calculated by the steadystate diffusion method. Oxygen and glucose uptake were calculated by the Fick principle (umbilical blood flow times the umbilical venoarterial blood glucose or oxygen difference).

Evaluation of fetal protein metabolism requires measurement of two of the three variables related as follows:

Synthesis $=$ breakdown + accretion $($ growth $)$

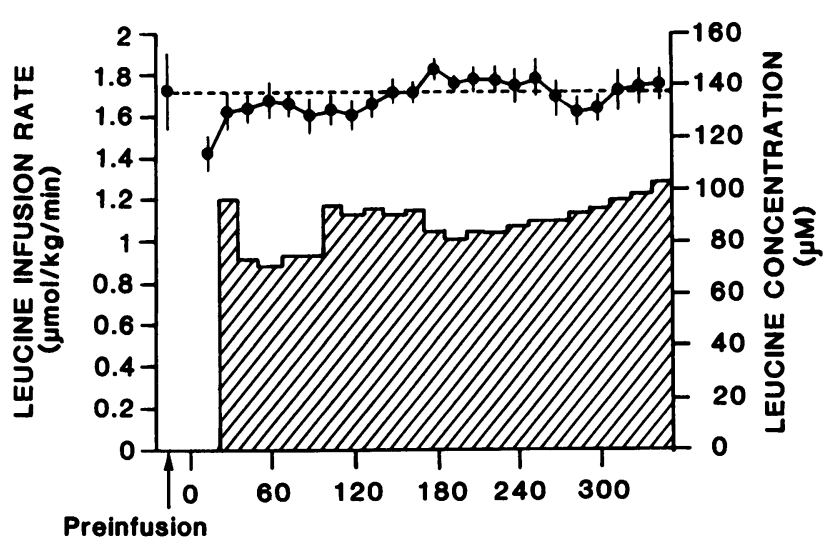

DURATION OF INSULIN INFUSION (min)

Figure 3. The rate of leucine infusion to the fetus and fetal serum leucine concentrations during insulin infusion in the protocol III portion of the experiments. Serum leucine concentration (shown as mean \pm SEM) was measured prior to the insulin and leucine infusions. Leucine was infused at the rates shown in an effort to keep serum leucine concentration at this concentration (shown as a dashed line). Throughout the infusion, serum leucine concentration was measured every 15 min until the sampling procedure (see Methods) began.
The following formulas were therefore used to estimate the rate of fetal protein synthesis.

Synthesis (nonoxidative disposal)

$=$ leucine disposal - leucine decarboxylation,

where leucine disposal was defined as:

Leucine disposal

$=($ infusion rate - transumbilical loss $) /$ specific activity.

The specific activity used for these calculations was that of plasma $\alpha$-ketoisocaproate, the transamination product of leucine. This specific activity has been used to estimate intracellular leucine specific activity $(20,21)$. In formula 3 , transumbilical loss was:

Transumbilical loss $=U B F\left\{\left(d p m_{\text {Leu-ua }}-d p m_{\text {Leu-uv }}\right)\right.$

$\left.+\left(d p m_{\text {Kic-ua }}-d p m_{\text {Kic-uv }}\right)\right\}$,

where $U B F$ was umbilical blood flow and $d p m_{\text {Leu-ua }}, d p m_{\text {Leu-uv }}$, $d p m_{\mathrm{Kic}-\mathrm{us}}$ and $d p m_{\mathrm{Kic}-\mathrm{uv}}$ represented the radioactivity as leucine and $\alpha$-ketoisocaproate in the umbilical artery and vein. In formula 2 , leucine decarboxylation was:

Leucine decarboxylation

$=\left\{U B F\left({ }^{14} \mathrm{CO}_{2 u a}-{ }^{14} \mathrm{CO}_{2 u v}\right)\right\} /$ specific activity,

where ${ }^{14} \mathrm{CO}_{2 u a}$ and ${ }^{14} \mathrm{CO}_{2 u v}$ were the blood $\mathrm{CO}_{2}$ radioactivity in the umbilical artery and vein, respectively.

Because the only fates for leucine are either metabolism or accretion into protein, the difference between the uptake of leucine across the placenta and its rate of metabolism (oxidation) was the rate of leucine accretion into protein.

Accretion = leucine uptake - leucine decarboxylation,

where leucine carbon uptake was:

Leucine uptake

$=U B F\left\{\left([L e u]_{\mathrm{uv}}-[L e u]_{\mathrm{ua}}\right)+\left([K i c]_{\mathrm{uv}}-[K i c]_{\mathrm{ua}}\right)\right\}$

where $[\mathrm{Leu}]_{\mathrm{uv}},[\mathrm{Leu}]_{\mathrm{ua}},[\mathrm{Kic}]_{\mathrm{uv}}$, and $[\mathrm{Kic}]_{\mathrm{ua}}$ were leucine and $\alpha$-ketoisocaproate concentrations in the umbilical vein and artery. 
Table I. Arterial Hematocrit, pH, Blood Gas, and Oxygen Content Values

\begin{tabular}{|c|c|c|c|c|c|c|}
\hline & \multicolumn{2}{|c|}{ Protocol I } & \multicolumn{2}{|c|}{ Protocol II } & \multicolumn{2}{|c|}{ Protocol III } \\
\hline & Control & Insulin & Control & Insulin & Control & Insulin \\
\hline Hematocrit (\%) & $31 \pm 1$ & $31 \pm 1$ & $29 \pm 1$ & $29 \pm 1$ & $28 \pm 1$ & $28 \pm 1$ \\
\hline pH & $7.36 \pm 0.01$ & $7.34 \pm 0.01$ & $7.35 \pm 0.01$ & $7.33 \pm 0.01$ & $7.36 \pm 0.01$ & $7.33 \pm 0.02^{*}$ \\
\hline $\mathrm{PCO}_{2}$ (torr) & $47.9 \pm 0.7$ & $49.8 \pm 1.5$ & $48.9 \pm 0.5$ & $50.7 \pm 0.7^{\ddagger}$ & $48.8 \pm 0.5$ & $51.2 \pm 0.6^{\ddagger}$ \\
\hline $\mathrm{Po}_{2}$ (torr) & $17.1 \pm 0.8$ & $16.2 \pm 0.9$ & $17.7 \pm 0.7$ & $16.4 \pm 1.0$ & $16.7 \pm 0.5$ & $15.2 \pm 0.6$ \\
\hline Base excess (meq/liter) & $0.8 \pm 0.6$ & $0.4 \pm 0.6$ & $0.6 \pm 0.5$ & $0.3 \pm 0.5$ & $1.3 \pm 0.5$ & $0.4 \pm 0.4^{*}$ \\
\hline Oxygen content $(m M)$ & $2.72 \pm 0.27$ & $2.37 \pm 0.29^{\ddagger}$ & $2.78 \pm 0.20$ & $2.34 \pm 0.19^{\ddagger}$ & $2.31 \pm 0.13$ & $1.84 \pm 0.15^{\ddagger}$ \\
\hline
\end{tabular}

All data are given as means \pm SEM. ${ }^{*}$ Significance at $P<0.01$; ${ }^{\ddagger}$ Significance at $P<0.05$.

Also calculated was fetal leucine clearance:

Leucine clearance $=$ leucine disposal $/[L e u]_{\mathbf{a}}$,

where leucine disposal was as calculated above and $[\mathrm{Leu}]_{\mathbf{a}}$ was arterial leucine concentration.

Statistics. The paired $t$ test was used to compare each variable with the control measurement made during that protocol. Differences were considered significant at $P<0.05$. All data are expressed as the mean \pm the standard error. Linear regression was by standard least squares techniques. Two lines were used instead of a single line when the broken line was a significantly better fit to the data than a single straight line (22).

\section{Results}

Fetal hematocrit, pH, blood gas and oxygen content values. There were no changes in fetal hematocrit coincident with fetal insulin infusion (Table I). Fetal blood gas analysis (Table I) showed a slight decrease in fetal pH during protocol III, a decrease that was coincident with a small increase of fetal $\mathrm{PCO}_{2}$ (protocols II and III), although arterial base excess fell slightly as well during protocol III. Fetal arterial oxygen content fell by $13 \%, 16 \%$, and $20 \%$ during insulin infusion in protocols I, II, and III, respectively (Table I).

Fetal glucose and leucine concentrations. In spite of insulin infusion, fetal euglycemia was maintained by infusion of glucose; i.e., in none of the three protocols was a change of fetal glucose concentration associated with the fetal infusion of insulin (Table II). Changing fetal insulin concentration from low to normal physiologic values (protocol I) was associated with a $16 \%$ decrease of fetal whole-blood arterial leucine concentration (Table II). The greater rate of insulin infusion used in protocol II was associated with a slightly greater $(21 \%)$ decrease of fetal leucine concentration. The same rate of insulin infu- sion was used in protocol III, but with the addition of an infusion of a mixture of amino acids including leucine the fall in leucine concentration was ameliorated $(8 \%)$ but not entirely prevented.

Fetal insulin and glucagon concentrations. The infusion of insulin to the fetus at a rate estimated to be $\sim 0.25 \mathrm{mU} / \mathrm{kg} /$ min (protocol I), increased fetal plasma insulin concentrations to values (Table II) that were indistinguishable from those of fetuses of normal ewes in our laboratory $(14.2 \pm 2.1 \mu \mathrm{U} / \mathrm{ml}$, as measured in 17 fetuses $6 \mathrm{~d}$ after catheterization and before any experimental procedures). Both protocol II and protocol III resulted in increases of fetal insulin concentration that were 6 and 7.5, respectively, times the increase noted during protocol I (Table II). Fetal infusion of somatostatin and glucagon during the control periods resulted in glucagon concentrations that were also indistinguishable from those of fetuses of normal ewes $(259 \pm 30 \mathrm{pg} / \mathrm{ml}$, as measured in 17 fetuses $6 \mathrm{~d}$ after catheterization and before any experimental procedures). There were no changes in fetal glucagon concentration during any of the three experimental protocols (Table II).

Fetal leucine infusion. Of the radioactive leucine infused to the fetus, between $20 \%$ and $24 \%$ was lost across the umbilical circulation as leucine (Table III). However, a small amount $(0-6 \%)$ of this loss returned to the fetus via the umbilical circulation as $\alpha$-ketoisocaproate. We corrected the loss of radioactivity as leucine for this small amount of return of radioactivity as $\alpha$-ketoisocaproate to give the total transumbilical radioactivity lost. No differences attributable to insulin infusion were found in the radioactivity that remained in the fetus in any of the three experimental protocols.

Fetal leucine kinetics. Fetal plasma $\alpha$-ketoisocaproate specific activity was not changed during insulin infusion in any of the three experimental protocols (Table IV). Fetal leucine dis-

Table II. Arterial Plasma Concentrations of Glucose, Leucine, and Hormones

\begin{tabular}{|c|c|c|c|c|c|c|}
\hline & \multicolumn{2}{|c|}{ Protocol I } & \multicolumn{2}{|c|}{ Protocol II } & \multicolumn{2}{|c|}{ Protocol III } \\
\hline & Control & Insulin & Control & Insulin & Control & Insulin \\
\hline Glucose $(m M)$ & $1.35 \pm 0.09$ & $1.33 \pm 0.08$ & $1.20 \pm 0.07$ & $1.23 \pm 0.09$ & $1.23 \pm 0.08$ & $1.24 \pm 0.08$ \\
\hline Leucine $(\mu M)$ & $233 \pm 20$ & $195 \pm 18^{*}$ & $222 \pm 22$ & $175 \pm 22^{*}$ & $205 \pm 25$ & $189 \pm 23^{\ddagger}$ \\
\hline Insulin $(\mu U / m l)$ & $9.2 \pm 2.1$ & $17.2 \pm 2.5^{*}$ & $7.7 \pm 1.9$ & $56.2 \pm 6.1^{*}$ & $7.3 \pm 1.7$ & $68.0 \pm 10.3^{*}$ \\
\hline Glucagon $(p g / m l)$ & $229 \pm 19$ & $253 \pm 52$ & $279 \pm 36$ & $289 \pm 32$ & $374 \pm 55$ & $399 \pm 55$ \\
\hline
\end{tabular}

All data are given as means \pm SEM. $*$ Significance at $P<0.001 ;{ }^{\ddagger}$ Significance at $P<0.02$. 
Table III. $l^{14}$ CJLeucine Infusion and Transumbilical Loss before and after Insulin Infusion during Each of Three Protocols

\begin{tabular}{|c|c|c|c|c|c|c|}
\hline & \multicolumn{2}{|c|}{ Protocol I } & \multicolumn{2}{|c|}{ Protocol II } & \multicolumn{2}{|c|}{ Protocol III } \\
\hline & Control & Insulin & Control & Insulin & Control & Insulin \\
\hline & \multicolumn{6}{|c|}{$d p m / k g$ per min } \\
\hline Infused & $135,100 \pm 6,100$ & $135,100 \pm 6,100$ & $137,700 \pm 6,100$ & $137,700 \pm 6,100$ & $135,700 \pm 6,500$ & $135,700 \pm 6,500$ \\
\hline \multicolumn{7}{|l|}{ Lost as } \\
\hline Leucine & $29,500 \pm 3,800$ & $28,500 \pm 1,300$ & $31,700 \pm 2,100$ & $32,900 \pm 3,600$ & $26,600 \pm 2,100$ & $27,400 \pm 3,300$ \\
\hline$\alpha$-Kic & $-1,600 \pm 500$ & $-1,100 \pm 300$ & $-1,600 \pm 700$ & $-1,000 \pm 300$ & $-100 \pm 400$ & $-1,700 \pm 300$ \\
\hline Total & $27,900 \pm 3,500$ & $27,400 \pm 1,300$ & $30,100 \pm 2,200$ & $31,800 \pm 3,500$ & $26,500 \pm 2,400$ & $25,600 \pm 3,300$ \\
\hline Remainder & $107,300 \pm 6,200$ & $107,700 \pm 5,500$ & $107,600 \pm 6,400$ & $105,800 \pm 7,400$ & $109,200 \pm 7,400$ & $110,100 \pm 7,000$ \\
\hline
\end{tabular}

All data are given as means \pm SEM. Abbreviation: $\alpha$-Kic, $\alpha$-ketoisocaprote.

posal fell by $7 \%$ during insulin infusion in protocol II (higher insulin concentrations and lower leucine concentrations), but was unaffected by the experimental conditions of the other protocols. As expected from the leucine disposal and concentration results presented above, fetal leucine clearance increased by $12 \%, 20 \%$, and $16 \%$ in protocols I, II, and III, respectively (Table IV). The uptake of leucine across the umbilical circulation by the fetus was unaffected by any of the experimental conditions ( Table IV). There was also uptake of $\alpha$-ketoisocaproate across the fetal circulation that ranged from $6 \%$ to $12 \%$ of the total uptake of the leucine carbon skeleton. Although the uptake of $\alpha$-ketoisocaproate fell during one experimental condition ( protocol II), the total uptake of leucine carbon skeleton remained unaffected by the conditions during insulin infusion in any of the three protocols. The rate of fetal leucine decarboxylation was also unaffected by the experimental conditions of protocols I and III. However, decarboxylation decreased during the period of higher insulin concentration and lower leucine concentration of protocol II (Table IV). When all 48 measurements of fetal decarboxylation rate are related to fetal leucine concentration, fetal decarboxylation rate is related to fetal leucine concentration $<190 \mu \mathrm{M}$, but not above that concentration (Fig. 4).

Fetal protein metabolism. The nonoxidative disposal of leucine (protein synthesis) was unaffected by the variation of insulin and leucine concentrations of the protocol I (Table V).
The rate of protein synthesis did however decrease under the conditions of protocol II (a greater increase of insulin concentration and a greater decrease of leucine concentration). Infusion of leucine to maintain more consistent leucine concentrations (protocol III) ameliorated the changes in protein synthetic rate induced by higher insulin concentrations. We were unable to detect any effect of changing fetal insulin concentration from low to normal values (protocol I) on the release of leucine from fetal protein breakdown. When fetal insulin concentration was varied over a wider range (protocol II) fetal protein breakdown decreased (Table V), even when fetal leucine infusion ameliorated the fall of fetal leucine concentration (protocol III). The accretion of leucine into fetal protein was unaffected by the infusion of insulin into the fetus when fetal leucine concentration was allowed to fall (protocols II and III). However, when fetal leucine concentration was maintained by fetal leucine infusion, there was a marked increase in accretion of leucine into protein (Table V).

\section{Discussion}

The role of insulin as an important regulator of fetal growth (9) has been suggested by the association of hypoinsulinemia with intrauterine growth deficiency in infants with pancreatic agenesis (8) and of hyperinsulinemia with increased fetal growth in infants of diabetic mothers (9). Moreover, increased protein

Table IV. Fetal Leucine Metabolism in Fetuses before and after Insulin Infusions for Each of Three Protocols

\begin{tabular}{|c|c|c|c|c|c|c|}
\hline & \multicolumn{2}{|c|}{ Protocol I } & \multicolumn{2}{|c|}{ Protocol II } & \multicolumn{2}{|c|}{ Protocol III } \\
\hline & Control & Insulin & Control & Insulin & Control & Insulin \\
\hline$\alpha$-Kic sp act $(d p m / n m)$ & $8.42 \pm 0.59$ & $8.64 \pm 0.40$ & $8.76 \pm 0.66$ & $9.26 \pm 0.59$ & $8.99 \pm 0.74$ & $8.76 \pm 0.59$ \\
\hline Clearance $(\mathrm{ml} / \mathrm{kg}$ per $\mathrm{min})$ & $48.3 \pm 4.4$ & $54.2 \pm 5.5^{\ddagger}$ & $48.0 \pm 4.2$ & $57.6 \pm 6.5^{\S}$ & $55.4 \pm 5.0$ & $64.4 \pm 5.9^{\prime \prime}$ \\
\hline Disposal & $12.96 \pm 0.61$ & $12.60 \pm 0.70$ & $12.55 \pm 0.89$ & $11.63 \pm 0.89^{*}$ & $12.38 \pm 0.78$ & $12.75 \pm 0.77$ \\
\hline \multicolumn{7}{|l|}{ Uptake as } \\
\hline Leucine & $3.91 \pm 0.41$ & $3.92 \pm 0.24$ & $3.68 \pm 0.42$ & $3.87 \pm 0.45$ & $3.59 \pm 0.33$ & $3.62 \pm 0.31$ \\
\hline$\alpha$-Kic & $0.28 \pm 0.07$ & $0.26 \pm 0.04$ & $0.49 \pm 0.10$ & $0.27 \pm 0.07^{1}$ & $0.22 \pm 0.05$ & $0.38 \pm 0.14$ \\
\hline Total & $4.19 \pm 0.46$ & $4.18 \pm 0.26$ & $4.17 \pm 0.47$ & $4.14 \pm 0.45$ & $3.82 \pm 0.36$ & $3.99 \pm 0.43$ \\
\hline Decarboxylation & $1.89 \pm 0.19$ & $1.77 \pm 0.13$ & $2.04 \pm 0.21$ & $1.77 \pm 0.17^{*}$ & $2.02 \pm 0.21$ & $2.01 \pm 0.17$ \\
\hline
\end{tabular}

All values are given as $\mu \mathrm{mol} / \mathrm{kg}$ per min with the exception of $\alpha-\mathrm{Kic}$ sp act and leucine clearance. All data are shown as means \pm SEM. Abbreviation: $\alpha$-Kic, $\alpha$-ketoisocaprote. Significance ${ }^{*}$ at $P<0.05$; $^{\ddagger}$ at $P<0.02 ;^{8}$ at $P<0.01$; $^{\prime \prime}$ at $P<0.001$; $^{\top}$ at $P<0.005$. 


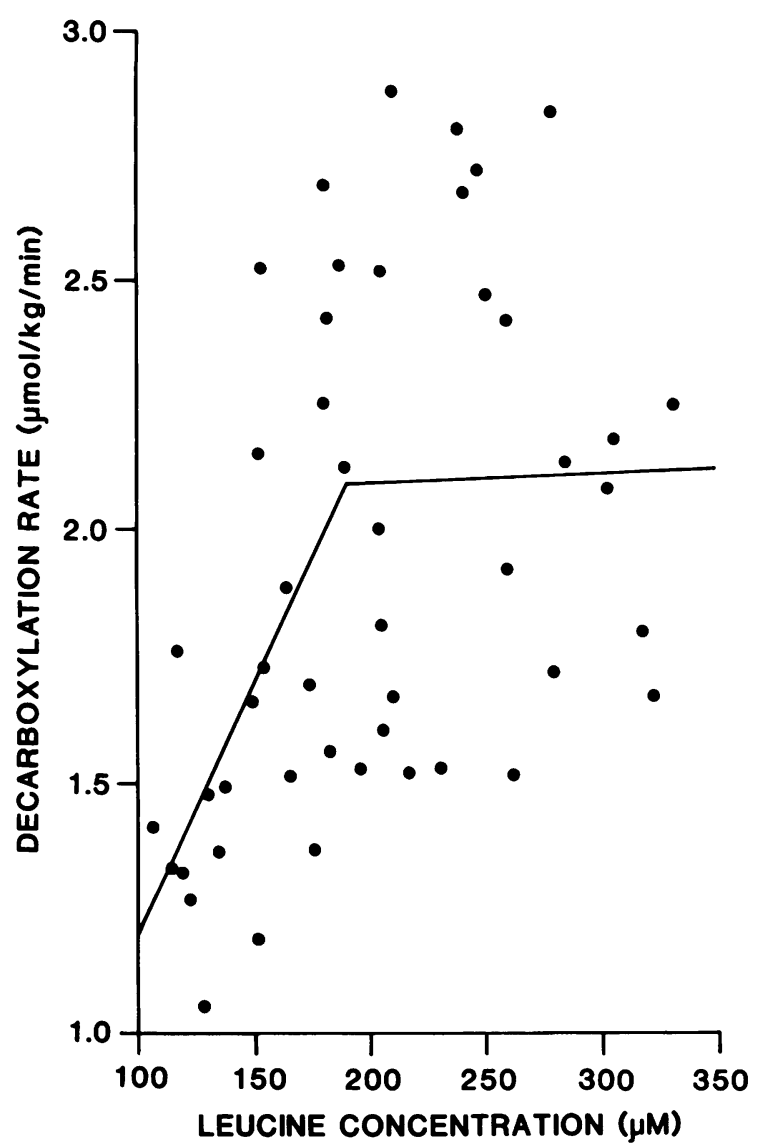

Figure 4. Fetal leucine decarboxylation rate as a function of fetal blood leucine concentration. Shown are all 48 data points from the eight animals. The data can be fit by a straight line (not shown), leucine decarboxylation $=0.00354$ (leucine concentration) $+1.20 ; r$ $=0.44$. However, the data are significantly $(P<0.05)$ better fit by the two straight lines shown, leucine decarboxylation $=0.00990$ (leucine concentration) $+0.21 ; r=0.61 ; P<0.001$; from 107 to 206 $\mu \mathrm{M}$ leucine, and leucine decarboxylation $=0.00023$ (leucine concentration $)+2.05 ; r=0.02, P=\mathrm{NS}$; from 206 to $332 \mu \mathrm{M}$ leucine. These two lines have less residual variance than any other two lines and meet at $190 \mu \mathrm{M}$ leucine.

content occurs in infants of diabetic mothers (23), suggesting that insulin could be important in regulating fetal protein accretion. Experimental confirmation that insulin regulates fetal protein accretion has given inconsistent results, however. Therefore, this study was undertaken to show whether variations of fetal insulin concentration affect fetal protein accretion and, if so, whether such changes in accretion are mediated pri- marily by changes in protein synthesis or changes in protein breakdown. Changing insulin concentration from low to normal caused no effect on leucine metabolism except blood leucine concentration fell. When insulin concentration was raised from low to high concentrations, fetal protein accretion was unaffected. As in adults $(4,6)$, however, leucine concentration fell and, concomitantly, both protein synthesis and breakdown decreased. In contrast, during amino acid infusion to maintain leucine concentration, insulin increased fetal protein accretion. This increased accretion was due to decreased fetal protein breakdown while fetal protein synthesis remained constant.

The limitations of the methods used in this investigation to measure fetal leucine and protein metabolism have been recently reviewed $(24,25)$. Probably the most fundamental assumption is that the specific activity of leucine is measured at the site of all its metabolic fates. Clearly, such a measurement is not possible in experiments such as this in which more than one in vivo measurement is planned. To best represent the general intracellular leucine specific activity, we chose to use the plasma specific activity of $\alpha$-ketoisocaproate (20, 21). Another factor that must be considered in studies such as this is the presence, unique to fetal life, of the umbilical circulation, a circulation that can lead to the loss or gain of both tracer and tracee to or from the placenta (and so the mother). We measured the net gain of tracee (both as leucine and as $\alpha$-ketoisocaproate) across the umbilical circulation, i.e., umbilical uptake. We have also found that between $20 \%$ and $24 \%$ of the radioactive leucine infused into the fetus was lost across the umbilical circulation. We have elected, as have others (12), to correct the fetal radioactive infusion rate for this loss before calculating fetal leucine disposal rate. Other investigators (26-28) have, however, elected to consider this loss of radioactivity part of the fetal disposal of leucine and calculate fetal leucine disposal before correction for transumbilical loss. In addition, the fetus receives a small amount of tracer (0-6\% of the leucine lost) back across the umbilical circulation as $\alpha$-ketoisocaproate, an amount that is in keeping with previous reports $(27,29)$ and that, though minimal, we included in our calculation of leucine disposal. Finally, the loss of labeled $\mathrm{CO}_{2}$ across the umbilical circulation is not corrected for retention in the bicarbonate pool of the fetus because Van Veen et al. (30) have shown that $99.6 \%$ of ${ }^{14} \mathrm{CO}_{2}$ infused into the sheep fetus is excreted across the umbilical circulation.

These experiments were designed to study only the effect of variations of fetal insulin and leucine concentrations. We infused glucose (15) so that glucose concentration did not change during insulin infusion. Neither fetal hematocrit nor arterial oxygen tension changed during insulin infusion. As expected, fetal oxygen content fell during insulin infusion, an effect we

Table V. Fetal Protein Metabolism before and after Insulin Infusion for Each of Three Protocols

\begin{tabular}{|c|c|c|c|c|c|c|}
\hline & \multicolumn{2}{|c|}{ Protocol I } & \multicolumn{2}{|c|}{ Protocol II } & \multicolumn{2}{|c|}{ Protocol III } \\
\hline & Control & Insulin & Control & Insulin & Control & Insulin \\
\hline Synthesis ( $\mu \mathrm{mol} / \mathrm{kg}$ per min) & $11.07 \pm 0.51$ & $10.83 \pm 0.62$ & $10.51 \pm 0.74$ & $9.81 \pm 0.78^{*}$ & $10.36 \pm 0.64$ & $10.73 \pm 0.65$ \\
\hline Breakdown $(\mu \mathrm{mol} / \mathrm{kg}$ per min $)$ & $8.77 \pm 0.68$ & $8.41 \pm 0.67$ & $8.38 \pm 0.84$ & $7.43 \pm 1.08^{*}$ & $8.57 \pm 0.71$ & $7.46 \pm 0.83^{\ddagger}$ \\
\hline Accretion $(\mu \mathrm{mol} / \mathrm{kg}$ per min) & $2.30 \pm 0.33$ & $2.42 \pm 0.21$ & $2.13 \pm 0.33$ & $2.39 \pm 0.40$ & $1.80 \pm 0.32$ & $3.27 \pm 0.30^{\S}$ \\
\hline
\end{tabular}

All data are means \pm SEM. Significance ${ }^{*}$ at $P<0.05 ;{ }^{\ddagger}$ at $P<0.005 ;{ }^{\S}$ at $P<0.001$. 
and others have noted previously $(31,32)$. We also noted a mild respiratory acidosis during insulin infusion (protocols II and III), a finding also noted during other studies of fetal hyperinsulinemia (32). These latter changes, though statistically significant, were of minimal magnitude and unlikely to be consequential in the present experiments. To avoid the possibility that changes of fetal glucagon concentration that may occur with fetal insulin infusion (33) would independently affect protein metabolism $(34,35)$, we infused somatostatin to minimize endogenous glucagon release and infused exogenous glucagon to maintain normal glucagon concentrations throughout the experiments. Somatostatin also decreases fetal growth hormone secretion (36), but this fact should not influence the present study for two reasons. First, fetal growth is not dependent on growth hormone (37). Second, any effects of somatostatin (either primary or secondary) on fetal protein metabolism should be equally present during both control and experimental conditions.

Estimates of fetal leucine disposal using the reciprocal pool model (i.e., calculated from $\alpha$-ketoisocaproate specific activity) have ranged from 10 to $14 \mu \mathrm{mol} / \mathrm{min}$ per $\mathrm{kg}(12,14,27$, 29 ), which are in excellent agreement with our control measurements. We found that fetal leucine disposal was unaffected by changing insulin concentrations from low to normal. However, disposal decreased during hyperinsulinemia when leucine concentration was allowed to fall (protocol II). Although two other laboratories $(12,38)$ found no effects of insulin on leucine disposal, in both studies, fetal leucine disposal was less during hyperinsulinemia but the change was not statistically significant. Thus their data are actually compatible with the present result, i.e., decreases in leucine disposal in response to insulin have occurred in each report. However, in these other experiments, as in protocol II of the present report, fetal leucine concentrations fell. The infusion of leucine to ameliorate the insulin-induced decrease of fetal leucine concentration (protocol III) prevented the fall in fetal leucine disposal. These changes in fetal disposal rate of leucine, therefore, are due to decreased fetal leucine concentration and are not the direct result of fetal hyperinsulinemia.

Another way to express substrate turnover or disposal is to use the concept of clearance of a substrate, in this case leucine. Leucine clearance is the total leucine disposal rate divided by its concentration, thereby normalizing the rate of disposal to the prevailing leucine concentration. In all of the protocols of the present experiment, fetal leucine clearance rose during hyperinsulinemia, a finding in keeping with the fall in leucine concentration common to each of the protocols. Because these changes in leucine clearance were associated with both hyperinsulinemia and decreased leucine concentration, it is not possible to determine if there is the same lack of effect of insulin on leucine clearance in fetuses as has been reported in adults (39).

One possible anabolic role for insulin might be to increase fetal uptake of amino acids, including leucine. Indeed, fetal amino acid nitrogen uptake significantly increases during hypoglycemic hyperinsulinemia (31). Estimates of normal fetal leucine uptake have ranged from 3.7 to $4.7 \mu \mathrm{m} / \mathrm{kg}$ per min (12, $14,27,29,40)$, values that agree with the control measurements of this study. The contribution of $\alpha$-ketoisocaproate to the uptake of leucine carbon skeleton has been less well studied. Loy et al. (27) found significant $\alpha$-ketoisocaproate uptake $(0.92 \pm 0.22 \mu \mathrm{m} / \mathrm{kg}$ per $\mathrm{min})$ representing about $\sim 19 \%$ of the total leucine carbon uptake. Our findings suggest a lower frac- tion of leucine carbon uptake as $\alpha$-ketoisocaproate (6-12\%) a finding more in concert with data $(4 \%)$ from Leichty et al. (29). Euglycemic hyperinsulinemia did not affect leucine uptake in one previous study (12) and our data, regardless of whether or not leucine was infused, agree with this conclusion.

If insulin does not increase transplacental leucine uptake (the only known source of exogenous leucine), how might it be anabolic? Amino acids in general, including leucine in particular, are taken up by the fetus in amounts greater than needed for accretion into protein. These findings, together with documentation of urea production by normal fetuses, led to the conclusion that amino acid oxidation provides a significant portion of the oxidative substrate for normally growing ovine fetuses. Fetal urea production decreases markedly during hypoglycemic hyperinsulinemia (40), suggesting that insulin may act to decrease fetal amino acid oxidation. In studies of euglycemic hyperinsulinemia in fetuses of well-fed ewes, however, insulin did not decrease leucine oxidation (12). Our data show that variation of insulin concentration from low to normal values (protocol I) did not affect fetal leucine oxidation, but that fetal hyperinsulinemia (protocol II) was associated with decreased fetal leucine oxidation. During infusion of leucine to alleviate the fall in leucine concentration (protocol III), fetal leucine oxidation rate remained constant. The change in leucine oxidation rate found in protocol II is, therefore, more likely due to the insulin-induced variation in leucine concentration than the change in insulin concentration itself. Indeed, we found a direct relation between leucine concentration and leucine oxidation at leucine concentrations $<190 \mu \mathrm{M}$. Our relationship is indistinguishable from that [leucine oxidation $(\mu \mathrm{mol} / \mathrm{kg}$ per $\min )=0.0316 \times$ leucine concentration $(\mu \mathrm{M})-$ 1.58] defined by Leichty et al. (29) in studies of fetal leucine metabolism during fasting and fetal glucose supplementation. Taken together, these two studies define a consistent regulation of leucine oxidation by fetal leucine concentration under a variety of physiological conditions. In this regard the fetus is similar to the adult in which leucine, through $\alpha$-ketoisocaproate, its transamination product, activates branched-chain $\alpha$-keto acid dehydrogenase, the enzyme regulating the oxidation of branched chain amino acids in a number of adult tissues (41).

The above measurements of fetal leucine metabolism may be used to calculate the flux of leucine to and from protein. Previous estimates of normal fetal nonoxidative leucine flux (i.e., the flux of leucine into protein) using similar methodology $(12,14,29)$ have ranged from 8.0 to $12.3 \mu \mathrm{mol} / \mathrm{kg}$ per min, values that agree with the control data from these experiments. Although changes of insulin concentration from low to normal values ( protocol I) had no effect on fetal protein synthesis, higher insulin concentrations ( protocol II) were associated with diminished fetal protein synthesis. These findings substantiate previous measurements during hypoglycemic hyperinsulinemia made by Young et al. (10). In addition, although Leichty et al. (12) noted no effect of insulin on fetal nonoxidative leucine disposal, in actuality, fetal protein synthesis fell by $20 \%$ in their experiments during hyperinsulinemia, a change that did not achieve significance. Consequently, their data are not necessarily in conflict with the other studies. In all three of these experiments, fetal amino acid concentrations decreased during insulin infusion. When we infused leucine to minimize the decrease of fetal leucine concentration (protocol III), the apparent effect of insulin on protein synthesis was completely abolished, a finding strongly suggesting that the effect observed 
on protein synthesis is related to changes in concentrations of amino acids rather than to changes of insulin concentration. Similar effects on protein synthesis of euglycemic hyperinsulinemia with and without amino acid infusion are reported in adults $(3,4,6)$.

Although insulin does not stimulate fetal protein synthesis, if fetal protein breakdown is diminished while protein synthesis remains constant, fetal protein accretion would increase, certainly an anabolic effect. Though a previous study (12) found no effect of hyperinsulinemia on fetal protein breakdown, a physiologically important effect could not be excluded (a 17\% decrease of fetal protein breakdown did not achieve statistical significance). In our experiments, when insulin concentrations were increased from low to hyperinsulinemic concentrations, protein breakdown decreased (protocol II), an effect that also occurred when amino acids were infused to maintain fetal leucine concentration (protocol III). In adults, insulin decreases the rate of appearance of leucine from protein breakdown also (3-6), a finding consonant with our findings in fetuses.

Fetal growth is marked by the ongoing accretion of amino acids into protein throughout gestation. Normal leucine accretion into fetal protein (by analysis of ovine fetal amino acid contents at various gestational ages ) is $\sim 2 \mu \mathrm{mol} / \mathrm{kg}$ per min at $120 \mathrm{~d}$ of gestation (42). None of the control measurements done for this study were different from this estimate in spite of the differences in methodology. Because both protein breakdown and protein synthesis decreased similarly in protocol II (hyperinsulinemia and lowered leucine concentration), fetal protein accretion, the difference between these two values, remained unaffected. During protocol III, when leucine was infused to maintain fetal leucine concentration, protein synthesis remained constant while protein breakdown fell. Consequently, the difference between synthesis and breakdown, the rate of accretion of leucine into fetal proteins, increased. In adults, the balance of protein synthesis and breakdown is similarly altered by insulin's reduction of protein breakdown so that the nongrowing adult changes to a positive protein balance (4).

In summary, these data are the first to show that the primary effect of insulin on protein metabolism in chronically catheterized fetuses of normally fed ewes is to decrease fetal protein breakdown. If amino acid concentrations are allowed to fall, this decreased protein breakdown is accompanied by decreased synthesis and no net accretion of protein occurs. If amino acid concentrations are maintained, however, fetal protein synthesis remains constant, and, because protein breakdown falls, fetal protein content increases. These findings serve to describe an important anabolic action of insulin in fetal life that is notably similar to its mode of action in adults.

\section{Acknowledgments}

The author thanks John Sweeley, Orissa Burghard, and Kristin Harley for their excellent technical assistance.

This research was supported by grant RO1 HD27455 from the National Institutes of Health.

\section{References}

1. Wool, I. G., and M. E. Krahl. 1959. Incorporation of ${ }^{14} \mathrm{C}$ amino acids into protein of isolated diaphragms: an effect of insulin independent of glucose entry. Am. J. Physiol. 196:961-964.
2. Fulks, R. M., J. B. Li, and A. L. Goldberg. 1975. Effects of insulin, glucose, and amino acids on protein turnover in rat diaphragm. J. Biol. Chem. 250:290298.

3. Hourani, H., P. Williams, J. A. Morris, M. E. May, and N. N. Abumrad. 1990. Effect of insulin-induced hypoglycemia on protein metabolism in vivo. Am. J. Physiol. 259 (Endocrinol. Metab. 22):E342-E350.

4. Castellino, P., L. Luzi, D. C. Simonson, M. Haymond, and R. A. DeFronzo. 1987. Effect of insulin and plasma amino acid concentrations on leucine metabolism in man. J. Clin. Invest. 80:1784-1793.

5. Denne, S. C., E. A. Liechty, Y. M. Liu, G. Brechtel, and A. D. Baron. 1991. Proteolysis in skeletal muscle and whole body in response to euglycemic hyperinsulinemia in normal adults. Am. J. Physiol. 261 (Endocrinol. Metab. 24):E809E814.

6. Flakoll, P. J., M. Kulaylat, M. Frexes-Steed, H. Hourani, L. L. Brown, J. O. Hill, and N. N. Abumrad. 1989. Amino acids augment insulin's suppression of whole body proteolysis. Am. J. Physiol. 257 (Endocrinol. Metab. 20):E839E847.

7. Tessari, P., R. Trevisan, S. Inchiostro, G. Biolo, R. Nosadini, S. V. De Kreutzenberg, E. Duner, A. Tiengo, and G. Crepaldi. 1986. Dose-response curves of effects of insulin on leucine kinetics in humans. Am. J. Physiol. 251 (Endocrinol. Metab. 14):E334-E342.

8. Lemons, J. A., R. Ridenour, and E. N. Orsini. 1979. Congenital absence of the pancreas and intrauterine growth retardation. Pediatrics. 64:255-256.

9. Fowden, A. L. 1989. The role of insulin in prenatal growth. J. Dev. Physiol. 12:173-182.

10. Young, M., J. Horn, and D. L. Noakes. 1979. Protein turnover rate in fetal organs: the influence of insulin. In Nutrition and Metabolism of the Fetus and Infant. H. K. A. Visser, editor. Martinus Nijhoff Publishers, The Hague. 19-27.

11. Johnson, J. D., T. Dunham, F. J. Wogenrich, R. E. Greenberg, R. B. Loftfield, and B. J. Skipper. 1990. Fetal hyperinsulinemia and protein turnover in fetal rat tissues. Diabetes. 39:541-548.

12. Liechty, E. A., D. W. Boyle, H. Moorehead, Y. M. Liu, and S. C. Denne 1992. Effect of hyperinsulinemia on ovine fetal leucine kinetics during prolonged maternal fasting. Am. J. Physiol. 263 (Endocrinol. Metab. 26):E696-E702.

13. Rattray, P. V., W. N. Garrett, N. E. East, and N. Hinman. 1974. Growth, development and composition of the ovine conceptus and mammary gland during pregnancy. J. Anim. Sci. 38:613-626.

14. Milley, J. R., and J. C. Sweeley. 1992. High-performance liquid chromatographic measurement of leucine and $\alpha$-ketoisocaproate in whole blood: application to fetal protein metabolism. J. Chromatogr. Biomed. Appl. 613:23-33.

15. DeFronzo, R. A., J. D. Tobin, and R. Andres. 1979. Glucose clamp technique: a method for quantifying insulin secretion and resistance. $\mathrm{Am}$. J. Physiol. 237 (Endocrinol. Metab. Gastrointest. Physiol. 6):E214-E223.

16. Hinks, N. T., S. C. Mills, and B. P. Setchell. 1966. A simple method for the determination of the specific activity of the carbon dioxide in blood. Anal. Biochem. 17:551-553.

17. Teunissen, M. W. E., J. E. Meerbrug-Van Der Torren, N. P. E. Vermeulen, and D. D. Breimer. 1983. Automated high-performance liquid chromatographic determination of antipyrine and its main metabolites in plasma, saliva, and urine, including dihydroxyantipyrine. J. Chromatogr. Biomed. Appl. 278:367-378.

18. Saifer, A., and S. Gerstenfeld. 1958. The photometric microdetermination of blood glucose with glucose oxidase. J. Lab. Clin. Med. 51:448-460.

19. Brown, L. L., P. E. Williams, T. A. Becker, R. J. Ensley, M. M. May, and N. N. Abumrad. 1980. Rapid high-performance liquid chromatographic method to measure plasma leucine: importance in the study of leucine kinetics in vivo. $J$. Chromatogr. 426:370-375.

20. Horber, F. F., C. M. Horber-Feyder, S. Krayer, W. F. Schwenk, and M. W. Haymond. 1989. Plasma reciprocal pool specific activity predicts that of intracellular free leucine for protein synthesis. Am. J. Physiol. 257 (Endocrinol. Metab. 20):E385-E399.

21. Schwenk, W. F., B. Beaufrere, and M. W. Haymond. 1985. Use of reciprocal pool specific activities to model leucine metabolism in humans. Am. J. Physiol. 249 (Endocrinol. Metab. 12):E646-E650.

22. Jones, R. H., and B. A. Molitoris. 1984. A statistical method for determining the breakpoint of two lines. Anal. Biochem. 141:287-290.

23. Naeye, R. L. 1965. Infants of diabetic mothers: a quantitative, morphologic study. Pediatrics. 35:980-988.

24. Bier, D. M. 1989. Intrinsically difficult problems: the kinetics of body proteins and amino acids in man. Diabetes Metabol. Rev. 5:111-132.

25. Milley, J. R. 1989. Fetal protein metabolism. Semin. Perinatol. 13:192210.

26. Kennaugh, J. M., A. W. Bell, C. Teng, G. Meschia, and F. C. Battaglia. 1987. Ontogenetic changes in the rates of protein synthesis and leucine oxidation during fetal life. Pediatr. Res. 22:688-692.

27. Loy, G. L., A. N. Quick, Jr., W. W. Hay, Jr., G. Meschia, F. C. Battaglia, and P. V. Fennessey. 1990. Fetoplacental deamination and decarboxylation of leucine. Am. J. Physiol. 259 (Endocrinol. Metab. 22):E492-E497. 
28. Van Veen, L. C. P., C. Teng, W. W. Hay, Jr., G. Meschia, and F. C. Battaglia. 1987. Leucine disposal and oxidation rates in the fetal lamb. Metab. Clin. Exp. 36:48-53.

29. Liechty, E. A., S. C. Denne, J. A. Lemons, and C. L. Kien. 1991. Effects of glucose infusion on leucine transamination and oxidation in the ovine fetus. Pediatr. Res. 30:423-429.

30. Van Veen, L. C. P., W. W. Hay, Jr., F. C. Battaglia, and G. Meschia. 1984. Fetal $\mathrm{CO}_{2}$ kinetics. J. Dev. Physiol. 6:359-365.

31. Milley, J. R., J. S. Papacostas, and B. K. Tabata. 1986. Effect of insulin on uptake of metabolic substrates by the sheep fetus. Am. J. Physiol. 251 (Endocrinol. Metab. 14):E349-E356.

32. Phillips, A. F., P. J. Porte, S. Stabinsky, T. S. Rosenkrantz, and J. R. Raye. 1984. Effects of chronic fetal hyperglycemia upon oxygen consumption in the ovine uterus and conceptus. J. Clin. Invest. 74:279-286.

33. Susa, J. B., P. A. Gruppuso, J. A. Widness, M. Domenech, G. K. Clemons, P. Sehgal, and R. Schwartz. 1984. Chronic hyperinsulinemia in the fetal rhesus monkey: effects of physiologic hyperinsulinemia on fetal substrates, hormones, and hepatic enzymes. Am. J. Obstet. Gynecol. 150:415-420.

34. Ostaszewski, P., and S. Nissen. 1988. Effect of hyperglucagonemia on whole-body leucine metabolism in immature pigs before and during a meal. $\mathrm{Am}$. J. Physiol. 254 (Endocrinol. Metab. 17):E372-E377.

35. Boden, G., L. Tappy, F. Jadali, R. D. Hoeldtke, I. Rezvani, and O. E.
Owen. 1990. Role of glucagon in disposal of an amino acid load. Am. J. Physiol. 259 (Endocrinol. Metab. 22):E225-E232.

36. De Zegher, F., J. Daaboul, M. M. Grumbach, and S. L. Kaplan. 1989. Hormone ontogeny in the ovine fetus and neonate. XXII. The effect of somatostatin on the growth hormone $(\mathrm{GH})$ response to $\mathrm{GH}$-releasing factor. Endocrinology. 124:1114-1117.

37. Liggins, G. C. 1974. The influence of the fetal hypothalamus and pituitary on growth. In Size at Birth, K. Elliott and J. Knight, editors. Associated Scientific Publishers, Amsterdam. 165-183.

38. Tsalikian, E., and W. Hamilton. 1991. Differential effect of hyperinsulinemia on fetal and neonatal amino acid kinetics. Pediatr. Res. 29:54A. (Abstr.)

39. Tessari, P., G. Biolo, S. Inchiostro, L. Saggin, A. Piccoli, and A. Tiengo. 1992. Relationship between plasma leucine concentration and clearance in normal and type 1 diabetic subjects. Acta Diabetol. 29:6-10.

40. Phillips, A. F., T. S. Rosenkrantz, J. A. Lemons, I. Knox, P. J. Porte, and J. R. Raye. 1990. Insulin-induced alterations in amino acid metabolism in the fetal lamb. J. Dev. Physiol. 13:251-259.

41. Aftring, R. P., K. P. Block, and M. G. Buse. 1986. Leucine and isoleucine activate skeletal muscle branched-chain $\alpha$-keto acid dehydrogenase in vivo. $\mathrm{Am}$. J. Physiol. 250 (Endocrinol. Metab. 13):E599-E604.

42. Meier, P., C. Teng, F. C. Battaglia, and G. Meschia. 1981. The rate of amino acid nitrogen and total nitrogen accumulation in the fetal lamb. Proc. Soc. Exp. Biol. Med. 167:463-468. 